\title{
Genograms and African American Families: Employing Family Strengths of Spirituality, Religion, and Extended Family Network
}

\author{
Annie McCullough Chavis ${ }^{1}$
}

\begin{abstract}
This article explores how genograms can serve as a multigenerational assessment for understanding family functioning and family processes. First, the author discusses how genograms are useful when depicting significant cultural patterns, beliefs, values, traditions, and family strengths in African American families. Next, she describes an integrated genogram model that may help social workers and practitioners recognize and employ recognized culturally connected family strengths and resources for work with African American families. Finally, a specific example of an intergenerational family genogram illustrates how practitioners can focus on extended family networks, spirituality, and religion as family strengths and resources in African American families.
\end{abstract}

Key Words: Genogram, African American families, family strengths, extended family network, spirituality, religion, family resources, intergenerational

${ }^{1}$ Annie McCullough Chavis, Ed.D., CMSW, ACSW is Assistant Professor, Department of Social Work, Fayetteville State University, 1200 Murchison Road, Fayetteville, NC, 28301. Electronic mail may be sent via the Internet to achavis@uncfsu.edu.

Author's Note: I would like to thank Sabrina McKeithan, Teaching \& Learning Instructional Technologist at Fayetteville State University, and Thomas W. Blume, editorial advisor, for their help with constructing the genogram.

The genogram is a valuable assessment tool used by social workers, therapists, counselors, and practitioners (Hartman \& Laird, 1983; Hartman, 1995; McGoldrick \& Gerson, 1985). Diagrammatically, the genogram is an intergenerational map of three or more generations of a family and a primary assessment tool that focuses on intergenerational patterns and relationships among family members (Goldenberg \& Goldenberg, 2000; Hartman, 1995; McGoldrick, Gerson, \& Shellenberger, 1999). It represents a large quantity of complex family information (Stanion \& Papadopoulos, 1997) and can effectively illustrate family data, family history, family systems, and 
intergenerational transmission (Hardy \& Laszloffy, 1995; Hartman \& Laird, 1983; Kilpatrick \& Holland, 2003; McGoldrick, Gerson, \& Shellenberger, 1999). The genogram can be especially useful when working with diverse cultural groupsespecially African American families - to promote cultural knowledge (Bean, Perry, \& Bedell, 2002; Thomas, 1998).

With families from diverse backgrounds, practitioners must be culturally competent to avoid culturally oppressive practices with clients (Chin, De La Cancela, \& Jenkins, 1993; Montague, 1996; Sue \& Sue, 1990). Effective practice with African American families requires understanding family strengths, resources, and dimensions of African American past and present family life. Such a perspective also involves the ability of practitioners to recognize and employ resources and strengths of African American families.

This article describes and promotes the use of the family genogram with African American families as a means of adapting identified family strengths and family resources of spirituality, religion, and extended family networks. They are identified as some of the major strengths of African American families (Billingsley, 1992, 1999; Hill, 1997; Hines \& Boyd-Franklin, 1996; Pipes, 1997). These family strengths have been applied to a Family Integrated Genogram (FIG) as an effective approach for understanding African American families.

\section{Review of Literature}

\section{Genograms}

A genogram is a graphic representation of family members and their relationships over at least three generations. As a visual assessment tool, the genogram can be used to trace family influences in various contexts as well as in the broader system (McGoldrick \& Gerson, 1985). Genograms have been used to help practitioners understand the family context, to trace behavior and problems of family members, and to identify patterns and issues within families. While understanding dysfunctional patterns is essential to treatment, identifying strengths is also the foundation that directs intervention. Genograms present a mechanism of identifying strengths and resources of individuals and families within a life cycle framework.

Genograms provide an exceptional mechanism to encourage insight and awareness by focusing on strengths, beliefs, and traditions in families. For example, genograms often provide a useful means of exploring religious and spiritual issues and their impact on clients' lives. Spiritually focused genograms have been suggested as an effective means for tapping the spiritual resources of families as well as cultural factors in the context of family dynamics (Dunn \& Dawes, 1999; Hodge, 2001). For example, Dunn and Dawes (1999) have illustrated how spiritual genograms with African American families are used to provide graphic representation of complex expressions of spirituality 
over three generations for assessment and intervention. A spiritually focused genogram allows therapists to understand clients' worldviews and the meaning they make of the world from a spiritual perspective. It also provides an excellent tool for exploring dimensions of human experiences and the spiritual dimensions of those experiences intergenerationally.

Genograms have been used successfully in assessment, counseling, marriage and family therapy, college teaching, and as mechanisms for increasing awareness in individuals and families concerning family history and family events. For example, McGoldrick and Gerson (1985) discussed the use of genograms in the field of marriage and family therapy as a tool for understanding individual development in the context of family dynamics. White and Tyson-Rawson (1995) described the use of genograms to assess gender dynamics in couples and families. Estrada and Haney (1998) and Thomas (1998) provided examples of how to use genograms to assess multicultural contexts with diverse families. Finally, Carter and McGoldrick (1998) have found genograms to be useful across the life span and encourage genograms use with all ages.

Genograms can also increase awareness and provide better insight into the personal family issues of graduate students. For example, genograms have been used as an educational tool by clinical sociologists to introduce and help students understand the sociological basis of family therapy and to deepen awareness of social transmission of families (Reed, 1994). Doughhetee (2001) demonstrated how genograms have been used successfully as teaching tools with graduate students in university settings as a method to connect systemic concepts to their family systems. Granello, Hothersalt and Osborne (2000) have even described the use of the academic genogram with doctoral students to trace academic lineage.

In summary, the literature indicates that genograms are useful tools that can be adapted to many different settings and circumstances. They can trace family influences in various contexts and explore diverse aspects of family strengths, resources, and cultural influences. The genogram provides an excellent means for exploring the African American family strengths of extended families and of religious and spiritual issues in a family context. Although genograms are useful for obtaining information on the complex family systems of African American families (Hines \& Boyd-Franklin, 1996), very little information is currently available on how to explore this tool to accurately understand African American families and their world.

\section{Historical Overview of African American Families}

An appreciation of African American families requires an understanding of the unique realities that have shaped their experiences (Chavis \& Waites, 2004). Unlike other immigrant groups, most African Americans were brought to this country in bondage and were cut off from their ethnic groups, beliefs, traditions of family life, and cultural heritage (Bennett, 1975). However, to understand African American families, it is important to note that despite being cut off from Africa, most draw from their West 
African roots and American roots. Therefore, within the African American family, cultural and historical contexts often serve as a close connection to the past, to the course of social change within the family system, and to the ecological systems in our society.

Billingsley (1992) incorporated the African concept in his definition of the African American family as follows: "The African American family is an intimate association of persons of African descent who are related to one another by a variety of means, including blood, marriage, formal adoption, informal adoption or by appropriation; sustained by a history of common residence in America; and deeply embedded in a network of social structures both internal and external to itself" (Billingsley, 1992, p. 28). Despite glaring oppression, racism, and invasive cutoffs from cultural heritage, traditions, and original languages, some African cultural values and heritage have survived within African American families in America. For example, values and traditions of spirituality, extended family, strong kinship ties, unity, and reverence for children and elders have roots in the African past (Hill, 1972, 1997; Nobles, 1974, 1991; Billingsley, 1992; Barnes, 2001). Through resilience, much of this heritage has evolved into many of the strengths and resources of present African American families.

\section{Family Strengths and African American Families}

A careful review of the literature suggests that the strengths perspective is "a way of viewing the positive behaviors of all clients by helping them see that problem areas are secondary to areas of strength..." (Glicken, 2004, p. 3). Saleebey (1997) suggested that to practice from a strengths perspective demands a different way of seeing clients, their environment and their current circumstance. Building on the strengths perspective to incorporate African American family strengths is a strategy and a technique that practitioners can use to work more effectively and adaptively with African American families and other families of color.

Family strengths are often linked to cultural traditions, and the family is the major context for ethnic or cultural reflections. McDaniel (1994) considers family strengths to be cultural assets that are transmitted through socialization from generation to generation and are merely adaptations or coping responses to contemporary racial or economic oppression. Hill $(1992,1997)$ provided practitioners and social workers with an excellent definition of strengths in Black families: Family strengths are those "traits that facilitate the ability of the family to meet the needs of its members and the demands made upon it by systems outside the family units" (Hill, 1997, p. 50).

For African American families, family strengths are necessary for the survival, maintenance, and advancement of family network, family dynamics, and family functioning. Recognizing and making use of the family strengths of African American families has the potential to help practitioners understand and solve many of the problems that families present. Although there are many family strengths cited in the literature (e.g., Hill, 1992, 1997; Boyd-Franklin, 2003), I have used the three strengths of 
spirituality, religion, and extended family kinship network because of their historical and intergenerational association with African American families.

\section{Spirituality and Religion}

Spirituality and religion have historically played important roles in the lives of African Americans (Mendes, 1982; Nobles, 1991; Taylor, Thornton \& Chatters, 1987, and many African Americans have been reared with a strong belief in God or a higher being (Boyd-Franklin, 1989, 2003). Spirituality and religion are generally understood to be distinct, but overlapping concepts (Carroll, 1998; Pellebon \& Anderson, 1999). Spirituality is defined as "experiences and expressions of one's spirit in a unique and dynamic process reflecting faith in God or a supreme being; connectedness with oneself, others, nature, or God; and an integration of the dimensions of mind, body, and spirit" (Meraviglia, 1999, p. 29). It is this belief in the sacredness and interconnectedness of mind, body, and spirit - and all life manifested in a quest for goodness - that practitioners must understand in working with spiritually connected African American families and other people of color. These spiritual beliefs and practices are usually connected to the survival system of families.

African Americans tend to express their spirituality through high levels of religious participation (Chatters, Taylor, \& Lincoln, 1999). Religion flows from spirituality and expresses the internal subjective reality of the two concepts (Hodge \& Williams, 2002). The term religion is defined for this article as the aspects of spirituality that are in the context of a formalized religious framework such as the church (Dunn \& Dawes, 1999) or other religious institution. Thus, religion is the formal institution that provides for the expression of spiritual beliefs and practices. An affiliation with a certain spiritual or religious ideology is viewed as a very important component of the emotional health of African Americans (Ellison, 1993; Lukoff, Turner, \& Lu, 1992).

In the context of African American culture, religious denominations and groups provide frameworks from which to practice specific beliefs, rituals, and rites (Mbiti, 1991). Common African American rituals include devotional reading, prayer, scripture study, and singing hymns (Hodge \& Williams, 2002). The Black Christian church is the primary means through which many African Americans express their religious and spiritual beliefs and values (Richardson \& June, 1997), but other sacred institutions are also prevalent. The church or other sacred institution is at the nucleus of many activities and is viewed as central to the functioning of the community (Boyd-Franklin, 1989; Moore, 1991).

Religious institutions in the African American community provide a spiritual foundation, offer a context for living, and represent a means of coping with adversity and preserving family patterns (Brashears \& Roberts, 1996; Cook, 1993; McAdoo \& Crawford, 1991). Prayer is often used by African Americans as a coping strategy; many African American women use prayer in response to interpersonal, emotional, and deathrelated problems. Religion and spiritual beliefs provide a foundation of inner strength and 
continue to be important and major strengths among African American families (Barnes, 2001; Hodge \& Williams, 2002).

\section{Extended Family Kinship Network}

One of the most enduring strengths and values of significance concerning African American families is the extended family and its strong kinship network (Billingsley, 1992; Hill, 1997). Values reflected in social practices based on the extended family and kinship network include strong values placed on children; strong, protective mothers; respect for elders and family unity (Boyd-Franklin, 1989, 2003; Hill, 1972, 1997); reciprocity; and family loyalty. Harvey (1985) emphasized the cultural continuity of kinship networks. "Kinship is the mechanism which regulates social relationships between people and almost all of the concepts pertaining to and connected to human relationships can be understood and interpreted through the kinship systems" (Harvey, 1985, p. 13).

The African American extended family often extends beyond a family circle and may include significant persons who are not related by blood or marriage. It provides emotional, social, and financial support in the form of advising, parenting, childcare, caretaking, and informal adoptions (Hill, 1972, 1997; Boyd-Franklin, 1989, 2003; Billingsley, 1992). Within the African American family system, family takes precedence over the individual (Boyd-Franklin, 1989) and when performing at an optimal level the extended family and kinship support network assist family members to adapt and survive throughout the family life cycle (Chavis \& Waites, 2004). The extended family kinship network can be a remarkable adaptive strength that practitioners can utilized to help families function and change despite obstacles, issues, and problems within the family systems.

\section{Family Integrated Genograms with African American Families}

The Family Integrated Genogram employed with African American families takes into account family strengths and intergenerational family history, values, beliefs, patterns, and communication. It builds on three identified strengths and several key questions adapted from Chavis and Waites (2004). The three areas correspond to the identified family strengths as follows:

- Spirituality and spiritual beliefs

- Religion and religious beliefs and practices

- Extended family kinship networks.

The FIG discloses family patterns and traditions that are often means that promote family resiliency and strengths and can be very useful in facilitating the helping process with clients. These questions (see Table 1) may assist practitioners in gathering relevant information for the FIG and a better understanding of family strengths utilized during assessment and intervention with African American clients and their families. 


\section{Interview Questions for African American Families}

1. What is the structure of your family?

- Who lives in your household?

- Who do you include in your extended family network?

- What are the roles of adult members?

2. How are elders and children viewed in your family?

- What role do elders play in your family?

- Who are considered the recognized leaders in your family?

$\circ \quad$ Who are the family members you admire? Please explain.

- How is caregiving to elders handled in your family?

- How are children cared for in your family?

3. How would you describe your family's and extended family's sense of unity?

- How would you describe your family's sense of "home"?

$\circ \quad$ Where do your family members reside geographically?

- How do you and your family members communicate with each other?

- How are thoughts and feelings expressed?

$\circ \quad$ What happened during time of crisis?

- How would you describe intergenerational relationships in your family, extended family?

4. What were significant transitions and/or critical life events in the history of your family, extended family?

- What events or situations have been stressful for you and your family?

○ When these events take place how do you or family member respond?

5. How do you and family members seek help and support?

- Where and to whom do you turn for support?

- What social supports are available to you?

6. What is the meaning of spirituality and religion for each member of your family going back three or more generations?

- How do different family members express religious and spiritual beliefs?

- How significant and important is prayer in your family and extended family?

- What is the level of involvement in organized religious institutions, i.e. church?

- What role does spirituality or religion play in the everyday lives of family members?

7. What are some of your family strengths and resources?

- What makes you feel proud about your family strengths?

- How have these strengths been passed on to you and others in your family?

- What are your family's resources?

- What are resources or supports available in your community?

○ How do you and your family use these resources? 


\section{The Genogram Approach}

The first step in constructing a FIG is to introduce the genogram as a device for visually exploring family history and family patterns in a manner that is culturally sensitive (Chavis \& Waites, 2004). During a standard genogram interview, the practitioner collaborates with the family to explore family history, family events, and significant family experiences. By participating in the drawing of the genogram, the individual and family can gain insight and understanding of their family history and patterns. Some of the information concerning demographics, chronologies, vertical, and horizontal repetitive information may be recorded within the genogram. Drawing the FIG with the family during the interview facilitates better interpretation and processing of the information. The interview process for the standard genogram is about 45 minutes, but adding additional questions to the interview could take longer.

Standard genogram symbols are drawn to indicate family structure, history and relationships for at least three generations. The index person (client or family) is drawn first. Parents, grandparents, great grandparents, siblings, spouses, children, and other family members are drawn next. Information is then gathered and recorded on significant family life cycle events such as births, deaths, causes of deaths, marriages, separations, divorces, remarriages, adoptions, abandonment, and cutoffs. The FIG incorporates other information such as occupations, education, religious affiliations, spiritual beliefs, extended family networks, family migrations, emotional and medical history, traditions, family practices and values, and other transitional life events. As illustrated in Table 1, items 2,6 , and 7 focusing on the importance of the extended family and the meanings of spirituality and/or religion to that family are contributions from the FIG. This information is written in proximity to the appropriate family member. A variety of lines are used to indicate communication patterns and the quality of relationships, such as close, fused, or distant.

\section{A Case Example}

Figure 1 provides an example of utilizing the FIG with an African American client family. Ella is a 56-year old African American woman. She is married and has three adult children. She sought counseling because of difficulties in accepting the recent death of her father. She identified strong spiritual and religious beliefs, close family bonds, and a sense of responsibility to her family and extended family. An FIG was chosen as a helpful tool in addressing the client's therapeutic goals. The practitioner began the interview and process by explaining the purpose and procedures of creating a genogram. Ella was shown a sample of a completed genogram and the list of questions (refer to Table 1). The practitioner and Ella explored information concerning the family and extended family, the suggested questions, and the three areas of strengths described previously. Information from the interview was graphically presented and recorded in the family integrated genogram (see Figure 1). 


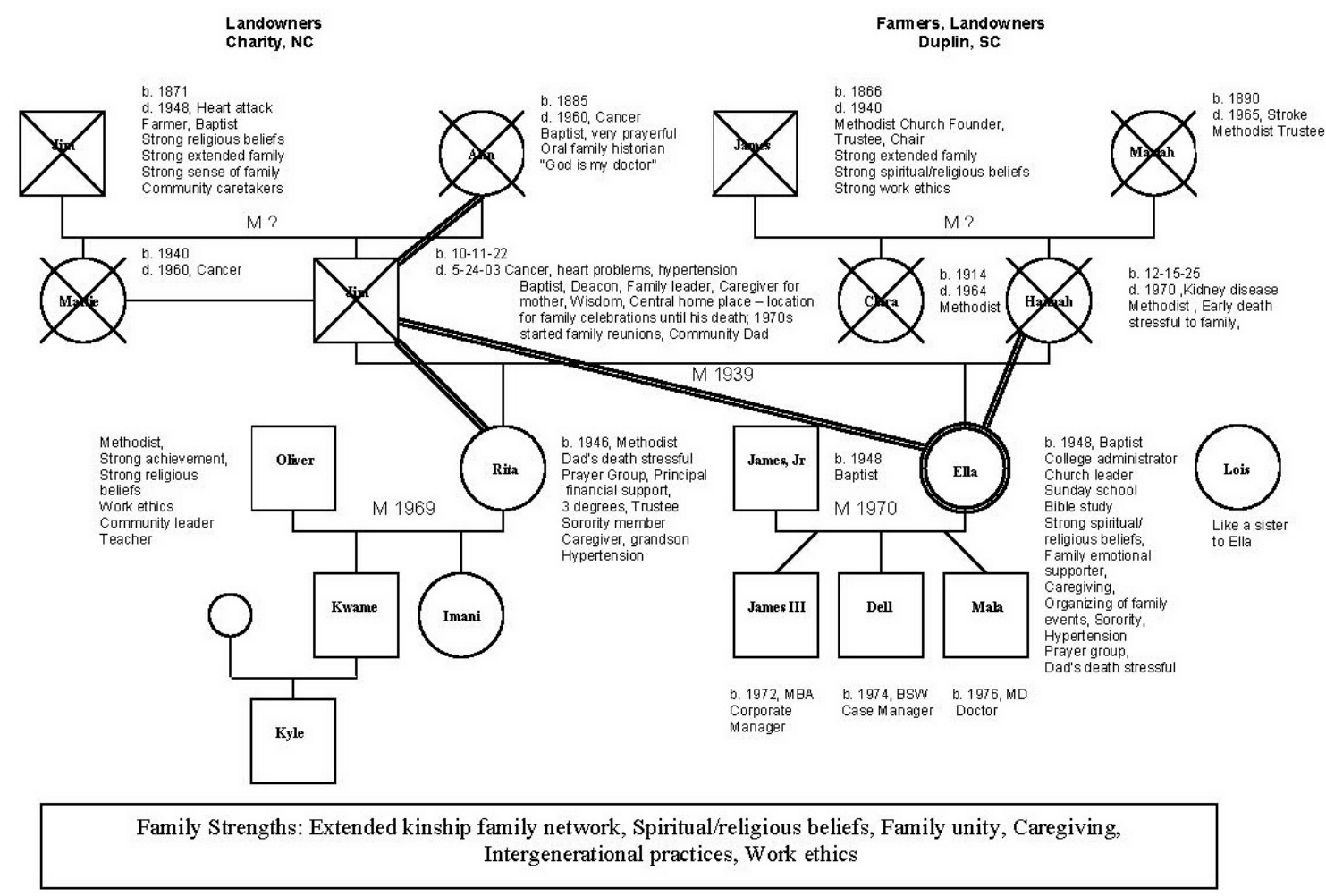

Figure 1. Integrated Family Genogram Model

Ella described feelings of sadness, anger, pain, and anxiety as a result of the death of her father and the fact that her sister is grieving extremely hard because their father lived with her prior to his death. Ella stated that she is considered "the strong one" in the family and feels compelled to be strong for her family and sibling, but feels overwhelmed, inadequate, and extremely sad concerning her father's death. Until his death, Ella's father played a central role in the family and extended family. He was the leader and provided family support, unity, and continuity. Until his death, his home was the center for most family celebrations.

Ella indicated that accepting her father's death is more difficult than expected and that her grieving is complicated because other family members rely upon her for emotional and spiritual support. The practitioner asked Ella to discuss her spirituality and the role religion played in her life. Ella indicated that she was raised as a Methodist, but changed to a Baptist after marriage. She is actively involved in her church and attends Sunday school and Bible study. She has a large and supportive church family. She reads her Bible, prays individually, and is part of a prayer group that includes her sibling, a close friend, and a Sunday school member. She views praying as essential-especially during times of stress and crisis. She believes in the interconnectedness of "mind, body, and soul." 
The social worker reviewed the genogram with Ella. She was able to emphasize Ella's strong religious and spiritual belief systems and the network of extended family in helping Ella and the family cope with her father's death. Ella was encouraged to share more of her feelings with her family and to consider how she could utilize her faith and church to help her cope with this family crisis and change. Ella stated that praying, scripture reading, and involvement in church activities strengthens her relationship with God. It also helps to sustain her during difficult times.

By participating in the constructing of the genogram and focusing on the African American family strengths of spirituality, religion, and extended family kinship networks, the practitioner and Ella were able to gain insight concerning Ella's family strengths and coping resources. These factors may be helpful in providing services to Ella and her family. Focusing on strengths offers solutions that can be instrumental in helping Ella to appreciate how she and her family are coping together with their father's death. The FIG can bring a shared focus to the discussion and can help the practitioner to understand Ella's resources and strengths.

\section{Conclusion}

The family genogram has become a widely accepted and valuable tool in family assessment and treatment. In addition, use of the FIG has important implications for work with African American families and other families of color. The genogram can allow for a clearer understanding of the client and the client's world. Constructing an FIG with African American families provides opportunities for often overlooked important family issues and life cycle events to be discussed, noting their impact on family functioning. It is important for social workers and practitioners to recognize that all ethnic groups, cultures, and families have strengths and resources that can assist in the assessment and treatment process. One of the most effective strategies for practice with African American families is to enhance and build on their strengths, and the Family Integrated Genogram (FIG) can assist in this process.

Accentuating positive aspects of African American families and utilizing family strengths have great potential to help solve issues and problems faced by families. Although weaknesses are not disregarded in this approach, the FIG process can help families meet the challenges and issues they face from a strengths perspective. As noted in the literature, families grow and build on strengths. Families can build on aspects found to be strengths and improve their well-being. A limitation of the FIG and this approach is that it may not fully explore all the strengths of Black families as noted by Hill (1972, 1997), Boyd-Franklin (1989, 2003), and others. However, the FIG is a culturally adaptable tool that can engage clients and help practitioners obtain significant family information to assist in their assessment and treatment. The Family Integrated Genogram was designed to focus on family strengths of extended family network, spirituality and religion. When used adaptively, it can help practitioners and social workers facilitate more appropriate assessment and treatment services for African American families. 


\section{References}

Barnes, S. (2001). Stressors and strengths: A theoretical and practical examination of nuclear single parent, and augmented African American families. Families in Society, 85 (5), 449-460.

Bean, R. A., Perry, B. J., Bedell, T. M., (2002). Developing culturally competent marriage and family therapist: Treatment guidelines for non-African American therapist working with African American families. Journal of Marital and Family Therapy, 28 (2), 153-164.

Bennett, J., (1975). The new ethnicity: Perspectives from ethnology. St. Paul: West Publishing

Billingsley, A. (1992). Climbing Jacob's ladder. New York: Simon \& Schuster.

Billingsley, A. (1999). Mighty like a river: The Black church and social reform. New York: Oxford University Press.

Boyd-Franklin, N. (1989). Black families in therapy: A multisystems approach. New York: Doubleday.

Boyd-Franklin, N. (2003). Black families in therapy: Understanding the African American experience $\left(2^{\text {nd }}\right.$ ed.). New York: Guilford.

Brashears, F., \& Roberts, M. (1996). The Black church as a resource for change. In S. L. Logan (Ed.), The Black family: Strengths, self-help, and positive change (pp. 181-191). Boulder, CO: Westview.

Carroll, M. (1998). Social work's conceptualization of spirituality. Social Thought; 18 (2), 1-13.

Carter, B., \& McGoldrick, M. (Eds.). (1998). The expanded family life cycle: Individual, family, and social perspectives. Needham Heights, MA: Allyn and Bacon.

Chatters, L. M., Taylor, R., \& Lincoln, K. D. (1999). African American religious participation: A multi-sample. Journal of Scientific Study of Religion, 36 (1), 132-145.

Chavis A. M., \& Waites, C. Genograms with African American families: Considering cultural context. Journal of Family Social Work, 8 (2), 1-19.

Chin, J. L., De La Cancela, V. \& Jenkins, Y. M. (1993). Diversity in psychotherapy: The politics of race, ethnicity, and gender. Westport, CT: Praeger.

Cook, D. A. (1993). Research in African American churches: A mental health counseling imperative. Journal of Mental Health Counseling, 15, 320-333.

Doughhetee, C. (2001). Using genograms as a tool for insight in college counseling. Journal of College Counseling, 4 (1), 73-77.

Dunn, A., \& Dawes, S. (1999). Spiritual-focused genograms: Key to uncovering spiritual resources in African American families. Journal of Multicultural Counseling and Development, 27 (4), 240-255. 
Ellison, C. G. (1993). Religious involvement and self-perception among Black Americans. Social Forces, 71 (4), 1027-1055.

Estrada, A., \& Haney, P. (1998). Genograms in a multicultural perspective. Journal of Family Psychotherapy, 9 (2), 55-62.

Glicken, M. D. (2004). Using the strengths perspective in social work practice. Boston: Pearson.

Goldenberg, H., \& Goldenberg, I. (2000). Family therapy: An overview ( $5^{\text {th }}$ ed.). Pacific Groves: CA: Brooks/Cole.

Granello, D., Hothersalt, D., \& Osborne, A. (2000). The academic genogram: Teaching for the future by learning the past. Counselor Education \& Supervision, 39 (3), 177-189.

Hardy, K. V., \& Laszloffy, T. A. (1995). The cultural genogram: Key to training culturally competent family therapist. Journal of Marital and Family Therapy, 21, 227-237.

Hartman, A. (1995). Diagrammatic assessment of family relationships. Families in Society, $76(2), 111-122$.

Hartman, A., \& Laird, J. (1983). Family-centered social work practice. New York: The Free Press.

Harvey, A. R. (1985). Traditional African culture as basis for the Afro-American church in America. In A. R. Harvey (Ed.), The Black family: An Afrocentric perspective (pp. 1-22). New York: United Church of Christ Commission on Racial Justice.

Hill, R. (1972). The strengths of African American families. Washington, DC: R \& B Publishers.

Hill, R. (1997). The strengths of African American families: Twenty-five years later. Washington, DC: R \& B Publishers.

Hines, P. M., \& Boyd-Franklin, N. (1996). African American families. In M. McGoldrick, J. Giordano, \& J. K. Peace (Eds.), Ethnicity and family therapy (pp. 66-84). New York: Guilford Press.

Hodge, D. R. (2001). Spiritual genograms: A generational approach to assessing spirituality. Families in Society, 82, 1, 35-48.

Hodge, D. R., \& Williams, T. R. (2002). Assessing African American spirituality with spiritual ecomaps. Families in Society, 11, 585-605.

Kilpatrick, A., \& Holland, T. (2003). Working with families: An integrative model by level of need ( $3^{\text {rd }}$ ed.). Boston: Allyn \& Bacon.

Lukoff, D., Turner, R., \& Lu, F. (1992) Transpersonal psychology research review: Psychoreligious dimensions of healing. Journal of Transpersonal Psychology, 24, 41-60.

Mbiti, J. S. (1991). Introduction to African religion ( $2^{\text {nd }}$ ed.). Portsmouth, NH: Heinemann. 
Mendes, H. A., (1982). The role of religion in psychotherapy with Afro-Americans. In B. A. Bass, G. E. Wyatt, \& G. J. Powell (Eds.), The Afro-American family: Assessment, treatment, and research issues (pp. 203-210). New York: Grune \& Stratton.

Meraviglia, M. (1999). Critical analysis of spirituality and its empirical indicators. Journal of Holistic Nursing, 17 (1), 18-33.

McAdoo, H. P., \& Crawford, V. (1991). The Black church and family support programs: The limits of individual efforts. Journal of Health and Social Behavior, 25, 406-423.

McDaniel, A. (1994). Historical racial differences in living arrangements of children. Journal of Family History, 19 (1), 57-77.

McGoldrick, M., \& Gerson, R. (1985). Genograms in family assessment. New York: Norton.

McGoldrick, M., Gerson, R., \& Shellenberger, S. (1999). Genograms: Assessment and interventions $\left(2^{\text {nd }}\right.$ ed.). New York: Norton.

Moore, T. (1991). The African American church: A source of empowerment, mutual help, and social change. Prevention in Human Services, 10, 147-167.

Montague, J. (1996). Counseling families from diverse cultures: A nondeficit Approach. Journal of Multicultural Counseling and Development, 24, 37-41.

Nobles, W. (1974). Africanity: Its role in Black families. The Black Scholar, 5, 10-17.

Nobles, W. (1991). African philosophy: Foundations of Black psychology. In R. L. Jones (Ed.), Black Psychology ( $3^{\text {rd }}$ ed., pp. 47-63). Berkeley, CA: Cobb \& Henry.

Pellebon, D., \& Anderson, S. (1999). Understanding the life issues of spiritually based clients. Families in Society, 80 (3), 229-238.

Pipes, W. H. (1997). Old time religion: Benches can’t say “Amen.” In H. P. McAdoo (Ed.), Black families (pp. 41-66). Thousand Oaks, CA: Sage.

Reed, M. (1994). Digging up family plots: Analysis of axes of variation in genograms. Teaching Sociology, 22, 255-259.

Richardson, B., \& June, L. (1997). Utilizing and maximizing the resources of the African American church: Strategies and tools for counseling professionals. In C. C. Lee (Ed.), Multicultural issues in counseling: New approaches to diversity ( $2^{\text {nd }}$ ed., pp. 155-170). Alexandria, VA: American Counseling Association.

Saleebey, D. (1997). The strengths approach to practice. New York: Longman.

Stanion, P., Papadopoulus, L., \& Bor, R. (1997). Genograms in counseling practice: Constructing a genogram (part 2). Counseling Psychology Quarterly, 10 (2), 139-148.

Sue, D. W., \& Sue D. (1990). Counseling the culturally different. New York: Guilford. 
Taylor, R., Thornton, M., \& Chatters, L. (1987). Black Americans' perceptions of the sociohistorical role of the church. Journal of Black Studies, 18, 123-138.

Thomas, A. J. (1998). Understanding cultural and worldview in family systems: Use of the multicultural genogram. Family Journal: Counseling and Therapy for Couples and Families, $6(1) 24-32$.

White, M. B., \& Tyson-Rawson, K. J. (1995). Assessing the dynamics of gender in couples and families: The genogram. Family Relations, 44, 253-260. 